\title{
Factors affecting the life and sustainable development of architectural of the rapid development city_— Taking Linyi city as an example
}

\author{
Jl Chaowen \\ Architectural School of Linyi University \\ jichaowen@lyu.edu.cn
}

Keywords: linyi city. building life. sustainable development. rapid development city

\begin{abstract}
Building life is closely related to the construction and environmental protection and sustainable urban development. This is the analysis of the factors affecting the life of the building, with the rapid development of the city as an example, Building these scientific planning of urban construction, vigorously develop the built environment-friendly city, and other cities to improve the quality of construction strategies for sustainable development.
\end{abstract}

\section{Introduction}

In recent years, many major buildings were demolished built only 10 to 20 years, causing some domestic experts, scholars, and the public's attention and questioned. According to currently short-lived building phenomenon, lots of scholars proposed advices to build a architecture whole life evaluation scientific analysis and economic evaluation, to extend the life of the building and to protect human survival environment from architecture ${ }^{[1-3]}$, environmental protection ${ }^{[4,5]}$ angles. In this paper, the rapid development stage in Linyi City as a case study to analyze the factors affecting the life of the building, in order to construct the corresponding city building strategy

\section{An old part of Linyi city and its buildings life}

Linyi City is located in the southeast of Shandong Province. With Yimeng Mountain upsate and on the verge of the Yi River. Linyi City has a glorious history and culture with the famous military strategist Zhuge Liang in Three Kingdoms period, calligrapher Wang Xizhi in the Eastern Jin Dynasty and Yan Gao ,Yan Zhuqing in Tang Dynasty as well. They were born here or lived here left the inspiring achievement. Since reform and opening, with the rapid development of trade and logistics industry, Linyi City has got the rapid development in the economic, social aspect .In 2012, the overall strength of the city ranked 48th in national-level ,finally won the National Civilized City, National Garden City, Chinese urban and rural construction model City and so on.

\subsection{Late but fast developing city}

1994 original county of Linyi City (now Lanshan) upgraded to prefecture-level cities, built-up area of 40 square kilometers, population 330,000, is medium-sized cities; In 2002, Linyi City built-up area of 62 square kilometers, population 654,000; In 2009, Linyi City built-up area expanded to 152 square kilometers, population increased to 156 million, which was the third largest city in Shandong only next to the Jinan, Qingdao in population and also has become the urban population up to the Huaihe River Basin cities; In 2012, Linyi City built-up area expanded to 202 square kilometers, the population increased to 1.85 million. ${ }^{[6]}$

\subsection{Old town with messy building layout}

The old town in Linyi city, except for a few buildings built in the fifties and sixties of the last century, The majority are built after the reform and opening up. There are three types of building .The first one ,each unit was approved by the relevant departments, in order to improve the working environment and worker housing .And these buildings, mostly use the construction pattern such as the workplace in the front, followed by residential parts which has messy layout, uneven quality. The adaptability and other ancillary units vary from the construction of the building to others. Secondly as housing reform after commercial real estate construction which meet people's 
basic needs of life easily, but with low volume rate. Thirdly, the residential of villages in the town who built the house themselves, lagged behind the pace of urban development, drifted away from the modern city management.

\subsection{The short life of the building}

The development and construction of Linyi City primarily built since the reform and opening up, with the launch and implementation of a new round of urban renovation project .The buildings which only built about 20-30 (years) age has doomed to be demolished. Such as the surrounding of Linyi People's Square has completed the upgrading, the original agricultural school teaching building, Xinhua Bookstore's staff housing and other buildings are less than 20 years of life; youth Palace Area renovation project in 2013 to start the demolition work, Linyi youth Palace, science museums and other are only 21 years of life; neighboring Area stadium demolition work has been completed (the plastic runway upgrades during this time) Linyi City Stadium is only 31 years of life. Built in 2003, Linyi City Stadium is only a 10-year life expectancy. Linyi City Area TV stations and other buildings in south area ,the demolition work things basically completed, the building has been demolished less than 30 years of life.

\section{The factors affecting Linyi City's building life}

\section{1 rapid urban development}

Urban land as the basis for the formation and development of the city , is the carrier of urban social , economic, political , cultural and other activities. Volume ratio is in the city of Linyi City development will enter a "breakthrough and blooming" stage of rapid development of the city .The rapid growth of urban population with the built-up area of the new city of skyscrapers, while the city center remained low throughout below a multi-storey building, occupying a land mass of urban areas .Central city land scarcity determines the volume rate of these plots low buildings will be demolished, inevitably affected by the rapid development of the city ,thereby improving land intensive utilization and satisfying with the rapid urban development needs. Such as the transformation of Linyi Youth Palace piece ( already granted ) plan ground floor area ratio $\leq$ $5.6,{ }^{[7]}$ to enhance the volume ratio of these two patches of greatly and improving the efficiency of land use .

\subsection{The historical limitations of layout}

Linyi City urban planning was the result of short-term immediate order, without considering the long-term development of the city. As the beginning of reform and opening up, allowing each unit built residential construction on their sites, resulting in scattered residential construction in particular, land layout fragmented. Residential, commercial, office, factory, etc. mixed with each other, very messy, especially the residential and industrial area are difficult to shape, serious interference so that water projects and the collective heating engineering are in the high cost of gas engineering and going slowly. With the rapid development of Linyi City, the original Lanshan as the main medium to long-term planning is also showing its historical limitations. This defect make the building with excellent construction quality are doomed to be demolished.

\subsection{The unmatched urban infrastructure}

Most of Linyi downtown building built in the 1990s, with less urban infrastructure and poor applicability. Roads are usually not up to the expected standards in City center, low green rate, short of leisure and fitness facilities and most residential buildings only to meet the living space and water (in wells) electricity, communications and other basic living needs. Building insulation, sound insulation, heat insulation, waterproof are poor. Many residential heating, gas and other life has yet to pass. Almost the only parts of the residential area are the residential buildings and the necessary roads. Facilities are close to zero.

\section{4 low construction standards}

Most of downtown buildings below the current building standards, such as the construction of prefabricated residential buildings, in the late 70 s of last century to the early 1990s, had been 
vigorously promoted. The seismic capacities of this house are poor. If a slightly larger earthquake occurred, the consequences would be disastrous. Linyi City, the center of the old district of 1980s and early 1990s almost all residential construction are brick structure prefabricated panels. Because of the way the building fell into disrepair and the limitations of these houses seismic and well below the stage-related security national standards, there is a huge security risk.

\section{Sustainable Development of Linyi City}

\subsection{Scientific planning and orderly putting forward the transformation}

Scientifically plan and rationally distribute the urban space, in order to construct one of the new city with rational layout, distinctive industries, infrastructure sharing, and the whole public services. This will be a major issue when start a new round of Linyi City during the city master plan revision .Facing in front of the ongoing overall planning revision, to promote the construction and transformation of the old town to the new adjustment. It's vulnerable to the current understanding; regional situation as a result of new limitations, Linyi City authorities should orderly transformation of the old, slow down the pace of the transformation of the old city. On the ground of full study and a basis for discussion on the appropriate speed propulsion and operation, not be so anxious to avoid due to a moment, a place, a person, a study of wrong decisions caused irreparable history will never regret.

\subsection{Accelerate environment-friendly and environment-friendly urban building construction}

Environment-friendly society is a form of human society in harmony with nature, the core meaning of human production and consumption activities and natural ecosystems, coordinated and sustainable development. Linyi City Development Research mode is suitable for China's national conditions, to accelerate the construction of Linyi City; environment-friendly and environment-friendly urban development is to accelerate the development of Linyi City and is the only way to healthy development. Therefore, the strengthening of energy, land, water, materials and other key technologies and new materials, new technologies, new processes, new products, the results of the application. In the project construction process, we consider the long-term factors, avoid housing design, irrational, function is not complete, low-tech, resulting in waste and destruction of resources; also based on our population and resources, in accordance with the development of circular economy and the strategic requirements of building a conservation-oriented society.

\subsection{To improve construction quality and sound architectural features}

Some buildings due to quality problems prematurely, even short-lived died. Although the building problems did not appear in Linyi City, the construction quality is not optimistic. Improving the quality of construction is also the only way to longevity of the building in Linyi City. Linyi City should improve design quality, construction standards, green building material selection, construction maintenance, and constantly improve the function of the building to meet the demand for building fitness. Extending the life of the building, build green, environmentally-friendly and environment-friendly city.

\section{Conclusion}

That is rapid development of the majority city especially in the eastern coastal city, Chinese urban development stage and the current stage of development of the western cities of developed countries is not consistent, We must learn from the experience of urban development stages corresponding Western countries, We explore a situation, regional situation, road urban development needs of the times, with scientific planning for the pilot, environment-friendly as fundamental to improve the quality of construction, building life to achieve economic, ecological, and promote the sustainable development of the city, which is currently Linyi City, as well as most of our city that must be solved to achieve. 


\section{References}

[1] Ning. Promote the overall design of the building to extend the life of [J]. Urban Development ,2006,01,42-43

[2] Lide Xi residential long-life design study [D], Beijing: Tsinghua University, 2007

[3] Xi before using slag cement powder can improve the building life [N], China Building Materials, 2011, 5, 10 Resources caused by the short-lived construction, energy, environmental issues analysis $[\mathrm{J}]$. Building energy efficiency,

[4] Humingyu etc. Resources, energy and environmental problems caused by the short-lived architectural analysis[J]. Building Energy.2008,01

[5] Yu Xia, Yang yong . Entire life cycle of building energy efficiency [J]. Ecological economy, 2009,05

[6]Linyi Municipal Bureau of Statistics. 2013 Yearbook [EB/OL]. Http : //www.stats-ly.gov.cn/linyi/tjsj/ndsj/79774.html.2013.12

[7] Linyi City Land Resources Bureau of Linyi City Land Resources Bureau auction of state-owned land use right transfer notice (Notice the word to let Pro MLR [2013] No. 34). Http://www.landchina.com/ 2013.12 